Utah State University

DigitalCommons@USU

4-3-2012

\title{
A High Efficiency 5kW Inductive Charger for Evs using Dual Side Control
}

Hunter H. Wu

Aaron Gilchrist

Ky Sealy

Daniel Bronson

Follow this and additional works at: https://digitalcommons.usu.edu/sdl_pubs

\section{Recommended Citation}

Wu, Hunter H.; Gilchrist, Aaron; Sealy, Ky; and Bronson, Daniel, "A High Efficiency 5kW Inductive Charger for Evs using Dual Side Control" (2012). Space Dynamics Lab Publications. Paper 147.

https://digitalcommons.usu.edu/sdl_pubs/147

This Article is brought to you for free and open access by the Space Dynamics Lab at DigitalCommons@USU. It has been accepted for inclusion in Space Dynamics Lab Publications by an authorized administrator of DigitalCommons@USU. For more information, please contact digitalcommons@usu.edu.

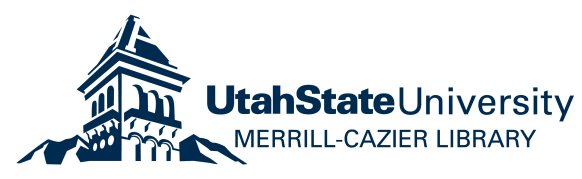




\title{
A High Efficiency 5kW Inductive Charger for EVs using Dual Side Control
}

\author{
Hunter H. Wu, IEEE Member, Aaron Gilchrist, Ky Sealy, IEEE Member, Daniel Bronson
}

\begin{abstract}
This paper presents the design of a $5 \mathrm{~kW}$ inductive charging system for electric vehicles (EVs). Over $90 \%$ efficiency is maintained from grid to battery across a wide range of coupling conditions at full load. Experimental measurements show that the magnetic field strength meets the stringent International Commission on Non-Ionizing Radiation Protection (ICNIRP) guidelines for human safety. In addition, a new dual side control scheme is proposed to optimize system level efficiency. Experimental validation showed that a $7 \%$ efficiency increase and $25 \%$ loss reduction under light load conditions is achievable. The authors believe this paper is the first to show such high measured efficiencies for a level 2 inductive charging system. Performance of this order would indicate that inductive charging systems are reasonably energy efficient when compared to the efficiency of plug-in charging systems.
\end{abstract}

Index Terms - Inductive Charging, Inductive Power Transfer, Resonant Power Conversion

\section{Nomenclature}

$\mathrm{V}_{\mathrm{dc}} \quad$ DC input voltage to the primary LCL converter

$\mathrm{V}_{\mathrm{ab}} \quad$ AC output voltage of $\mathrm{H}$-bridge (Figure 4)

$\left(\mathrm{V}_{\mathrm{ab}}\right)_{1}$ Fundamental component of AC output voltage

$\mathrm{V}_{\text {oc }} \quad$ Voltage measured when secondary IPT pad is open circuited

$\mathrm{V}_{\text {out }} \quad$ DC output voltage of secondary decoupling circuit (Figure 5)

$\mathrm{V}_{\mathrm{bd} \_ \text {on }}$ Voltage drop portion of boost converter diode

$\mathrm{V}_{\text {hs_on }}$ Voltage drop portion of IGBT

$V_{\text {rd on }}$ Voltage drop portion of secondary rectifier diodes

$\mathrm{I}_{\mathrm{b}} \quad$ AC bridge inductor current of LCL converter (Figure 4)

$\mathrm{I}_{\mathrm{c}} \quad$ Capacitor current through $\mathrm{C}_{1}$ of LCL converter (Figure 4)

$\mathrm{I}_{1} \quad$ Primary track current (or current flowing through inductor coil)

$\mathrm{I}_{1 \text { max }}$ Maximum primary track current in LCL converter

$\mathrm{I}_{\mathrm{sc}} \quad$ Current measured when secondary IPT pad is short circuited

$\mathrm{I}_{2} \quad$ Secondary receiver pad inductor current (Figure 5)

$\mathrm{I}_{\mathrm{ac}} \quad$ AC current through secondary rectifier (Figure 5)

Manuscript received Nov 31, 2011, accepted for publication February 24, 2012.

Copyright (c) 2009 IEEE. Personal use of this material is permitted. However, permission to use this material for any other purposes must be obtained from the IEEE by sending a request to pubs-permissions@ieee.org.

This material is based upon work supported by the Department of Energy under Award Number DE-EE0003114. This report was prepared as an account of work sponsored by an agency of the United States Government. Neither the United States Government nor any agency thereof, nor any of their employees, makes any warranty, express or implied, or assumes any legal liability or responsibility for the accuracy, completeness, or usefulness of any information, apparatus, product, or process disclosed, or represents that its use would not infringe privately owned rights. Reference herein to any specific commercial product, process, or service by trade name, trademark, manufacturer, or otherwise does not necessarily constitute or imply its endorsement, recommendation, or favoring by the United States Government or any agency thereof. The views and opinions of authors expressed herein do not necessarily state or reflect those of the United States Government or any agency thereof
$\mathrm{I}_{\mathrm{Ldc}} \quad$ DC inductor current through $\mathrm{L}_{\mathrm{dc}}$ (Figure 5)

$\mathrm{I}_{\text {out }} \quad$ DC output current of secondary decoupling circuit (Figure 5)

$\mathrm{Q}_{1} \quad$ Quality factor of primary LCL resonant converter

$\mathrm{Q}_{2} \quad$ Total quality factor of the secondary resonant circuit [1]

$\mathrm{Q}_{2 \mathrm{v}} \quad$ Voltage quality factor of the secondary resonant circuit [2]

$\mathrm{Q}_{2 \mathrm{i}} \quad$ Current quality factor of the secondary resonant circuit [2]

$\mathrm{Q}_{2 \mathrm{vm}}$ Maximum voltage quality factor at maximum load condition

$\mathrm{k} \quad$ Coupling coefficient

$\mathrm{k}_{\min } \quad$ Minimum coupling coefficient within operating range

$\mathrm{k}_{\max }$ Maximum coupling coefficient within operating range

SU Uncompensated power of an IPT pad (defined as $\mathrm{V}_{\mathrm{oc}} * \mathrm{I}_{\mathrm{sc}}[3]$ )

$\omega \quad$ Operating frequency of IPT system

M Mutual inductance between primary and secondary IPT pads

$\mathrm{L}_{b} \quad$ Bridge inductance of LCL converter

$\mathrm{L}_{1} \quad$ Self-inductance of primary IPT pad (Figure 4)

$\Delta \mathrm{L}_{1} \quad$ Change in primary IPT pad inductance due to height variations

$\mathrm{L}_{2} \quad$ Self-inductance of secondary IPT pad (Figure 5)

$\Delta \mathrm{L}_{2} \quad$ Change in secondary IPT pad inductance due to height variations

$\mathrm{L}_{\mathrm{dc}} \quad$ DC inductance of secondary decoupling circuit

$\mathrm{L}_{\text {leq }} \quad$ Equivalent primary IPT pad inductance with series tuning (2)

$\mathrm{L}_{2 \mathrm{eq}} \quad$ Equivalent secondary IPT pad inductance with series tuning (9)

$\mathrm{C}_{1} \quad$ Parallel tuning capacitor on the primary (Figure 4)

$\mathrm{C}_{1 \mathrm{~s}} \quad$ Series tuning capacitor on the primary (Figure 4)

$\mathrm{C}_{2} \quad$ Parallel tuning capacitor on the secondary (Figure 5)

$\Delta \mathrm{C}_{2}$ Equivalent change in secondary tuning capacitance due to variations in $\mathrm{L}_{2}$

$\mathrm{C}_{2 \mathrm{~s}} \quad$ Series tuning capacitor on the secondary (Figure 5)

$\mathrm{X}_{1} \quad$ Reactance of the LCL converter (with series tuning) [4]

$\mathrm{X}_{2} \quad$ Reactance of the secondary resonant tank (with series tuning)

$\sigma \quad$ Conduction angle control variable of SVC [5]

D Control duty cycle of secondary boost converter

$Z_{p} \quad$ Equivalent load impedance of secondary circuit with detuning effects

$Z_{\mathrm{r}} \quad$ Reflected impedance on the primary from secondary side

$\operatorname{Re}\left(Z_{\mathrm{r}}\right)$ Reflected resistance on the primary from secondary side

$\operatorname{Im}\left(Z_{\mathrm{r}}\right)$ Reflected reactance on the primary from secondary side

$\mathrm{P}_{\max }$ Maximum transferrable power of IPT system

$\mathrm{P}_{\text {out }}$ Output power transferred in IPT system

$\mathrm{R}_{\mathrm{dc}} \quad$ DC equivalent resistance of the battery under steady state

$\mathrm{R}_{\mathrm{dc} \_ \text {min }}$ Maximum loading condition ( $18 \Omega$ for this paper)

$\mathrm{R}_{\mathrm{ac}} \quad$ Equivalent $\mathrm{AC}$ resistance of load from resonant tank

$\mathrm{R}_{\mathrm{dc}} \quad$ Equivalent DC resistance of battery under steady state (Figure 16)

$\mathrm{R}_{\mathrm{b}} \quad$ ESR of AC bridge inductor and two times linear on resistance of IGBT

$\mathrm{R}_{\mathrm{L} 1} \quad$ ESR of primary IPT pad

$\mathrm{R}_{\mathrm{L} 2} \quad$ ESR of secondary IPT pad

$\mathrm{R}_{\mathrm{Ldc}}$ ESR of DC inductor and two times linear on resistance of rectifier bridge

$\mathrm{R}_{\mathrm{bd} \_ \text {on }}$ Linear on resistance portion of boost converter diode

$\mathrm{R}_{\mathrm{hs} \text { _on }}$ Linear on resistance portion of IGBT

$\alpha \quad$ Normalized detuning capacitance ratio (16)

$\eta_{\mathrm{r} 1} \quad$ Efficiency of primary LCL converter without voltage drop

$\eta_{\mathrm{cl}} \quad$ Efficiency of primary LCL converter without linear resistance loss

$\eta_{\mathrm{b} 2}$ Efficiency of secondary boost converter without voltage drop

$\eta_{\mathrm{c} 2}$ Efficiency of secondary boost converter with linear resistance loss

$\eta_{\mathrm{r} 2} \quad$ Efficiency of secondary resonant circuit

$\eta \quad$ Efficiency of system neglecting switching losses

\section{INTRODUCTION}

$\mathrm{O}$ ver the last decade, growing environmental awareness and fossil fuel price shocks have driven strong growth in 
demand for plug-in hybrid electric vehicles (PHEVs) and pure electric vehicles (EVs) [6].

EVs connect to the electricity grid to recharge. Currently, the most conventional method is plug-in charging, where a copper connected cable forms the power link. The charging power level varies from level 1 over $1 \mathrm{~kW}$ to level 2 up to $19.8 \mathrm{~kW}$ [7]. It usually takes an overnight charge to bring a depleted battery up to full charge. There are several disadvantages to this method, which have led to the investigation of inductive charging technology. Inductive charging (or Inductive Power Transfer [IPT]) uses time varying magnetic fields to jump the air gap of a car chassis and wirelessly recharge a vehicle parked over a transmitter. The advantages of inductive charging over plug-in systems can be summarized as follows:

- Convenience - IPT systems can be completely autonomous. Vehicles start to charge right away when they are parked over a charger. This was found to be extremely helpful for people who find connecting a charging plug that is substantially larger and heavier than the typical NEMA-5 plug troublesome.

- Weather proof - IPT systems can be embedded underground, eliminating issues related to exposure to rainy, snowy, or freezing environments

- Anti-vandalism - Public plug-in systems are prone to vandalism such as theft of the copper cable. Because potential vandals and thieves cannot easily see IPT system infrastructure, it seems far less likely they will dig under the road to target it.

- Low risk of hazards - the wire used in a plug-in system may be a potential trip hazard for people; given that in a public setting the charging environment is usually close to the road, the level of danger imposed by another vehicle hitting someone is not negligible.

Inductive charging systems usually tolerate a wide range of height and misalignment conditions such as vertical height variations caused by tire pressure changes, vehicle loading conditions, and thickness of snow on the car park, as well as horizontal misalignment, which are usually caused by a driver's parking tolerances. Mechanical alignment systems can be used as a solution; however, if the inductive charging system can handle these tolerances, it is preferable in terms of reliability and cost. The system level efficiency for an inductive charging system is very important and it is ideal to maintain very high charging efficiencies over a wide range of height and misalignment conditions.

There have been a number of publications outlining inductive charging. The first research project that looked at inductive charging with some depth is the UC Berkeley PATH program in the late 70's [8]. However, due to the limited semiconductor switching frequency at the time, the system was limited to a few hundred $\mathrm{Hz}$, efficiency was poor, and costs were quite high. Later, a preliminary charging system at much higher frequencies was developed [9]. Both this system and the system described in a more recent publication [10] had bifurcation issues and their copper coils did not have ferrite to shape the magnetic field. As a result, when placed next to the ferrimagnetic chassis of the vehicle, these systems detuned and did not operate correctly. More recently, a multi-path receiver pickup was presented for inductive charging; however, the system level efficiency was not given [10]. There have been a number of good publications on pad design for vehicle charging [11-14], but these did not provide a thorough overall design process. A research initiative from KAIST has shown great progress for charging buses while traveling slowly in-motion; however, the system efficiency has been limited to $85 \%$ for systems with power levels around $60 \mathrm{~kW}$ [15-18]. Here, other factors like cost of the components maybe more important and this limits efficiency. Similar to this initiative, other groups have also started to look at in-motion charging $[19,20]$ for light duty vehicles; however, the research is still preliminary and a full system level hardware solution has not been implemented. There has also been some research looking at $\mathrm{MHz}$ power transmission, which holds promise [21, 22]; however, these are still in early stages of research and the designs have been predominantly focused on coils.

The block diagram of the inductive charging system proposed in this paper is shown in Figure 1. On the primary (transmitter) side, the circuit is composed of a PFC, rectifier and a LCL load resonant converter. The PFC and rectifier stage converts single phase AC to $400 \mathrm{~V}$ DC with very high efficiencies. The main controller of the system is on the transmitter side, and monitors the entire primary and secondary (via wireless communications) control feedback signals. Optical, RFID, or position detection algorithms are installed to provide feedback to the driver on the current parking position. Everything on the secondary side is carried on-board the vehicle. The parallel decoupling circuits convert the high frequency AC back to $300 \mathrm{~V}$ DC to recharge the onboard battery.

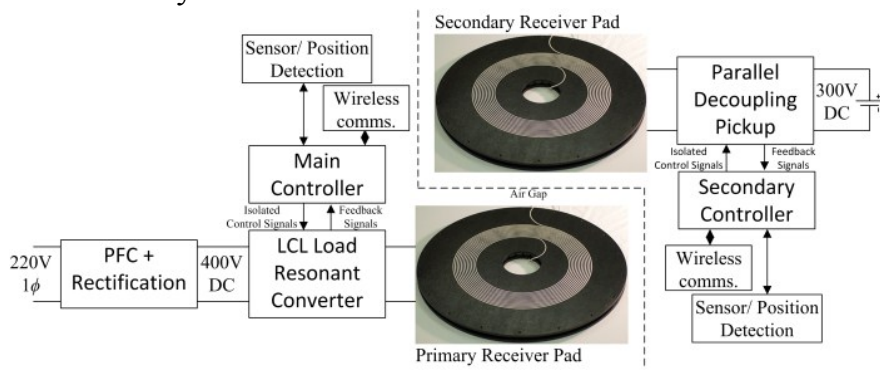

Figure 1. Circular pad structure and dimension (Top View).

This paper presents the patent-pending design of an inductive charger that can maintain a system level efficiency above $90 \%$ from grid to battery while operating over its entire coupling range (a change of $100 \%$ in coupling). To the best knowledge of the authors, this paper is the first to demonstrate that inductive charging has achieved such high efficiencies, potentially making the technology comparable to plug-in charging systems.

The paper is organized as follows: Section II describes the design procedure for the inductive charging system. Section III describes the new controller proposed to enhance the efficiency performance at lighter load conditions. Experimental results are provided to validate the design process. Finally, conclusions are drawn. 


\section{Outline Of 5KW System Design}

\section{A. Circular Pad Design}

Due to wide acceptance for EV charging systems, a wellknown circular pad topology was chosen for this application $[12,23-26]$. Recent publications of new pad designs [11, 13, $14,16,27]$ that can achieve higher coupling coefficients with the same height to pad dimension ratio can also be easily applied to this system design. The maximum pad size installable under the vehicle is limited by its maximum width. However, to meet magnetic field safety standards, the size of the pad needs to be much smaller in practice. The International Commission on Non Ionizing Radiation Protection (ICNIRP) guidelines, a standard currently adopted in many EU and Oceania countries, is commonly used to determine the maximum magnetic field exposed to humans by a wide range of new inductive charging standards (like SAE-J2954, ISO/IEC PT61980). Here, an $813 \mathrm{~mm}$ diameter circular pad design (32") is chosen with dimensions shown in Figure 2. The ferrite bar length, the bar position, and the inner and outer coil radius follows the design optimization outlined in [12]. The receiver and transmitter pads are identical in structure. Each long ferrite leg is composed of 3 linear I cores with dimensions of $101 \times 25 \times 25 \mathrm{~mm}$. The winding are composed of 1300 strands of AWG36 Litz wire. It should be noted that the volume of ferrite bars used is overrated for magnetic flux density saturation purposes and this pad can transfer up to $10 \mathrm{~kW}$ of power if a larger power converter is used. Each pad weighs $20.4 \mathrm{~kg}$ (45 lbs).

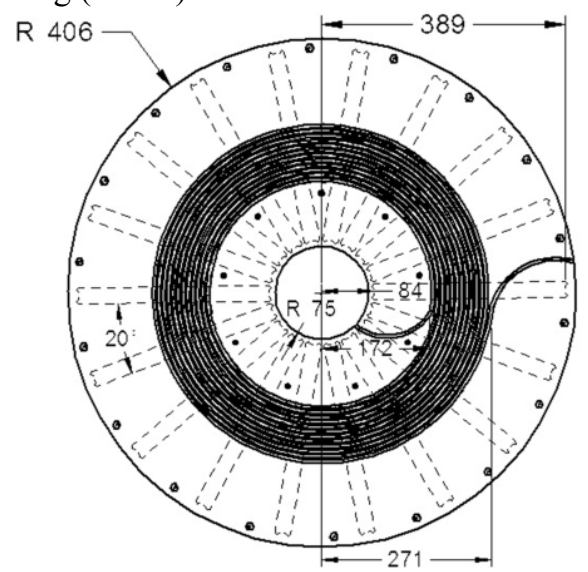

Figure 2. Circular pad structure and dimension in $\mathrm{mm}$ (Top View).

To satisfy the overall $5 \mathrm{~kW}$ power requirement, the wellknown IPT power equation [1] is used:

$$
P_{\max }=\omega I_{1}{ }^{2} \frac{M^{2}}{L_{2}} Q_{2}=S U \cdot Q_{2}
$$

It was decided for this particular design, $\mathrm{I}_{1}$ will be limited to $40 \mathrm{~A}$, the operating frequency at $20 \mathrm{kHz}$ and $\mathrm{Q}_{2}$ limited to 5 . The choice of these design parameters is well suited to current available technology and the general design strategy can be found in [28]. Due to the length of the paper, the details of this process will not be included. The coupling part $\left(\mathrm{M}^{2} / \mathrm{L}_{2}\right)$ in (1) is dependent on the height and size the IPT pads chosen. The measured mutual and self-inductance profiles of the two pads under vertical and horizontal misalignment are shown in Figure 3. FEM simulations were also performed with JMAG and had consistent results within 3\% error. However, to keep the graph clear, simulation results are not shown. To satisfy a minimum of $5 \mathrm{~kW}$ of output power, a minimum mutual inductance from (1) must be met. In this system, it corresponds to $\mathrm{M}>30 \mathrm{uH}$ (and a coupling coefficient $\mathrm{k}>0.17$ ). Here, the maximum mutual inductance is chosen to be two times the minimum to keep within practical limitations of electronic component stress (further outlined in section II.B). For this system, the operating height extends from $175 \mathrm{~mm}$ to $265 \mathrm{~mm}$ at zero horizontal variation, and the horizontal misalignment from $0 \mathrm{~mm}$ to $170 \mathrm{~mm}$ at a vertical height of $200 \mathrm{~mm}$. This was deemed sufficient for most vehicles and reasonable driver parking ability (with feedback). Although only one set of horizontal misalignment measurement is shown to keep the graph clear, the overall 3D operational zone defined by the minimum coupling condition can be easily approximated by a simple cone shape with its base located above the transmitter pad. For example, no horizontal misalignment is allowed at a height of $265 \mathrm{~mm}$ being the tip of the cone, and a horizontal misalignment of $250 \mathrm{~mm}$ is allowed at a height of $170 \mathrm{~mm}$ being the bottom of the cone. The unloaded quality factor of the pad during operation is around 350 with different horizontal and vertical alignment conditions.

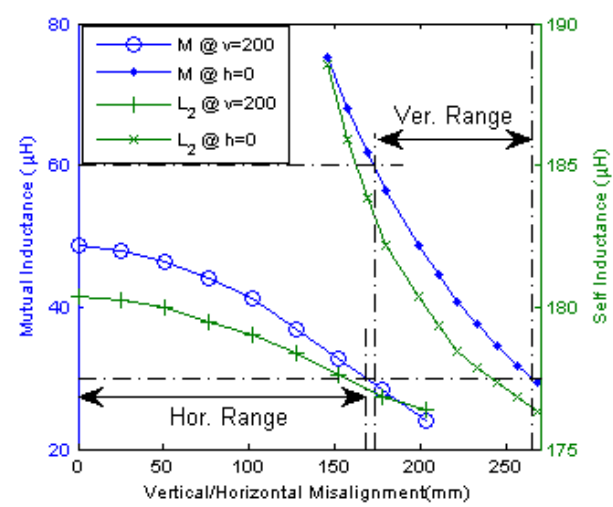

Figure 3. Misalignment conditions for vertical and horizontal misalignment. $\mathrm{h}=0$ trend represents the profile of vertical misalignment under zero horizontal offset. $\mathrm{v}=200$ trend represents the profile of horizontal misalignment under $200 \mathrm{~mm}$ of height separation.

\section{B. LCL Converter Design}

The LCL load resonant converter shown in Figure 4 is chosen in this application because of the following advantages:

- The inverter bridge only has to supply the real power required by the load and any losses in the resonant tank. The high track currents are constrained to self-circulate in the resonant tank. For example, in most practical applications (where $\mathrm{Q}_{1}>1$ ), $\mathrm{I}_{\mathrm{b}}<\mathrm{I}_{1}$ (Figure 4), the switches have low conduction losses and a high converter efficiency is achieved.

- The output current is independent of load, making it a constant current source ideal for IPT applications. The primary pad current $I_{1}$ is only dependent on one control variable and hence the power output, or uncompensated power (SU) in (1), is directly controlled.

To design the LCL converter, the reactance of each branch 
is tuned by the conventional equation in [4]:

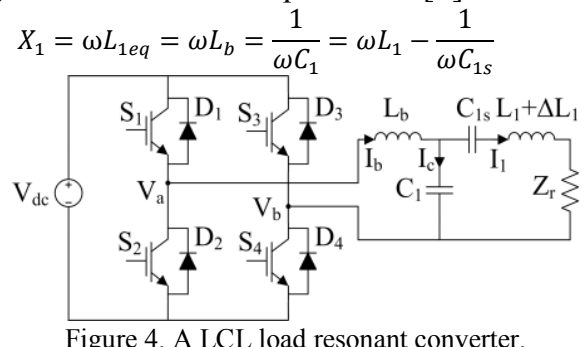

Figure 4. A LCL load resonant converter.

Here $C_{1 s}$ is a series tuning capacitor to reduce the reactance of the pickup to a desired operating value. For this system, phase shift control or symmetric voltage cancellation (SVC) [5] is used to directly control the track current $\left(\mathrm{I}_{1}\right)$ with one control variable $(\sigma)$. To determine the track current under SVC, and assuming fundamental mode analysis, the following equation is used:

$$
I_{1}=\frac{2 \sqrt{2} V_{d c}}{\pi X_{1}} \sin \left(\frac{\sigma}{2}\right)
$$

The maximum obtainable track current can be determined when $\sigma$ is set to $180^{\circ}$. For the LCL converter, the specifications in Table I are calculated according to the design equations. The reflected impedance of a fully tuned parallel resonant tank [9] is given by:

$$
Z_{r}=\frac{\omega^{2} M^{2}}{Z_{2}}=\omega \frac{M^{2}}{L_{2 e q}}\left(Q_{2 v}-1 \cdot j\right)
$$

It should be noted from (4) that a constant reflected capacitive reactance is in series with the track inductor and one method to directly compensate for this in the design [5] is to short the secondary pickup inductance with its series tuning capacitor $\left(\mathrm{C}_{2 \mathrm{~s}}\right)$. This gives a new operating range of (161$172 \mathrm{uH})$. The system is ideally designed for $200 \mathrm{~mm}$ and the inductance of $168 \mathrm{uH}$ is used in determining $\mathrm{X}_{1}$.

As the coupling changes in the system, a complex phenomenon of variations in both $\mathrm{Z}_{\mathrm{r}}$ and $\Delta \mathrm{L}_{1}$ will occur. This will cause the bridge current $\mathrm{I}_{\mathrm{b}}$ to increase beyond its nominal value. The general form of $\mathrm{I}_{\mathrm{b}}$ in an LCL network [4], can be written as:

$$
I_{b}=\frac{\left(V_{a b}\right)_{1}}{X_{1}{ }^{2}}\left(j \omega \Delta L_{1}+Z_{r}\right)
$$

When the system is allowed to change its coupling by $100 \%$ $\left(\mathrm{k}_{\max }=200 \% \mathrm{k}_{\min }\right)$, the reflected impedance would change by 4 times according to (4). However during this coupling change, $\mathrm{I}_{1}$ and $\left(\mathrm{V}_{\mathrm{ab}}\right)_{1}$ is controlled to be inversely proportional to the coupling change with a variation of 2 times [29], hence the maximum $I_{b}$ must be at least 2 times the minimum. With variations in the primary self-inductance of the pad, the bridge current inductor is designed to handle $42 \mathrm{~A}$, which is 2.5 times the minimum current.

TABLE I. Design Parameters For LCL Converter.

\begin{tabular}{|c|c|c|c|}
\hline Parameter & Value & Parameter & Value \\
\hline $\mathrm{V}_{\mathrm{dc}}$ & $400 \mathrm{~V}$ & $\mathrm{C}_{1 \mathrm{~s}}$ & $663 \mathrm{nF}$ \\
\hline $\mathrm{X}_{1}$ & $9.21 \Omega$ & $\mathrm{L}_{1}$ (Figure 3$)$ & $177-188 \mathrm{uH}$ \\
\hline $\mathrm{I}_{1 \_ \text {max }}$ & $39 \mathrm{~A}$ & $\mathrm{~L}_{1 \text { short }}$ & $161-172 \mathrm{uH}$ \\
\hline $\mathrm{L}_{\mathrm{b}}$ & $73.3 \mathrm{uH}$ & $\omega$ & $1.257 \times 10^{5} \mathrm{rad} / \mathrm{s}$ \\
\hline $\mathrm{C}_{1}$ & $885 \mathrm{nF}$ & & \\
\hline
\end{tabular}

\section{Secondary Parallel Pickup with Decoupling Control}

A well-known parallel pickup with decoupling control [1, 2, 29-31], shown in Figure 5, is chosen for the receiver circuit for the following reasons:

- The parallel resonant circuit acts as a current source under steady state conditions [29], and would be ideal for charging most types of batteries.

- The decoupling controller is easy to use and can regulate the output voltage of the pickup to any desired value by simply controlling the duty cycle of the switch $S_{b}$ [1]. In addition, the secondary side control acts as a protection feature to the batteries if the wireless communications link is temporarily not operational.

- Operating the decoupling controller switch at high switching frequencies will produce a reflected impedance to the primary $\left(Z_{\mathrm{r}}\right)$ that is constant, and current drawn from the power supply will ideally have minimal EMI compared to slow switching operation.

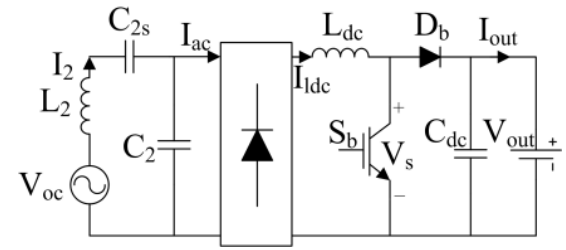

Figure 5. Parallel Pickup with decoupling circuit.

Here, the open circuit voltage from first principles is given by:

$$
V_{o c}=j \omega M I_{1}
$$

And if the battery can be modeled as an equivalent DC resistance under steady state, then the output power is given by a well-known relationship [29]:

$$
P_{\text {out }}=P_{\max }(1-D)=\omega I_{1}{ }^{2} \frac{M^{2}}{L_{2 e q}} Q_{2 v}(1-D)
$$

where

$$
\begin{gathered}
Q_{2 v}=\frac{R_{a c}}{X_{2}}=\frac{\pi^{2}(1-D)^{2} R_{d c}}{8 \omega L_{2 e q}} \\
X_{2}=\omega L_{2 e q}=\left(\omega L_{2}-1 / \omega C_{2 s}\right)=1 / \omega C_{2}
\end{gathered}
$$

$\mathrm{Q}_{2 \mathrm{v}}$ defined in (8), is different from the $\mathrm{Q}_{2}$ used in (1). $\mathrm{Q}_{2}$ is the overall quality factor of the secondary resonant circuit and can be defined as the product of the voltage $Q\left(Q_{2 v}\right)$ and current $\mathrm{Q}\left(\mathrm{Q}_{2 \mathrm{i}}\right)$ [2]. The key part of the design strategy is to choose an $\mathrm{L}_{2 \text { eq }}$ in (9) that will meet the maximum power requirements in (7). The design parameters are shown in Table II. The $\mathrm{V}_{\mathrm{oc}}$ parameter is not given here, since it is dependent on the coupling condition and primary track current used. The main purpose of $\mathrm{L}_{\mathrm{dc}}$ is to keep the rectifier current continuous and the guidelines to choosing it can be found in [32]. TABLE II. Design Parameters For IPT Pickup.

\begin{tabular}{|c|c|c|c|}
\hline Parameter & Value & Parameter & Value \\
\hline $\mathrm{V}_{\text {out }}$ & $300 \mathrm{~V}$ & $\mathrm{~L}_{\mathrm{dc}}$ & $550 \mathrm{uH}$ \\
\hline $\mathrm{X}_{2}$ & $10.6 \Omega$ & $\mathrm{I}_{\text {out }}$ & $0-17 \mathrm{~A}$ \\
\hline $\mathrm{C}_{2}$ & $745 \mathrm{nF}$ & $\mathrm{C}_{2 \mathrm{~s}}$ & $666 \mathrm{nF}$ \\
\hline $\mathrm{L}_{2}$ & $177-188 \mathrm{uH}$ & & \\
\hline
\end{tabular}

\section{High Efficiency Dual Side Control}

One critical aspect of the inductive charging system is to control the power (or current) used to charge the on-board 
battery. By grouping (3) and (7),

$$
P_{\text {out }}=\frac{V_{d c}{ }^{2}}{\omega^{2}} \frac{M^{2}}{L_{1 e q}{ }^{2} L_{2 e q}{ }^{2}} R_{d c}(1-D)^{3} \sin ^{2}\left(\frac{\sigma}{2}\right)
$$

It can be seen from equation (10), that the power delivered to the battery is dependent on both control variables $\mathrm{D}$ and $\sigma$, which are more conventionally known as decoupling [29] and primary track current control [33]. Several ways have been proposed in the past to implement a control algorithm. One option is to use primary track current control by itself $[34,35]$. Another more recent development would be to control the primary track current via $\sigma$ when $\mathrm{M}$ varies. Duty cycle control is used against load resistance changes. In essence, $I_{1}$ is controlled so that it is inversely proportional to $\mathrm{M}$ governed by (6) to keep $V_{o c}$ fixed, and $D$ is used to control power output due to load changes by (10). This type of approach will be referred to as secondary control in this paper. However, it will be shown in the next section that both of these methods are non-optimal control strategies for obtaining the highest overall system efficiency. In the subsequent sections, a new dual side control strategy is proposed to achieve the highest efficiency for the system with load and coupling variations.

\section{A. Optimal Efficiency Analysis}

The efficiency analysis approach taken here breaks the system into separate sections and analyzes the efficiency of each section individually. One assumption of the efficiency analysis is that only conduction losses are considered, because the switching losses of the H-bridge on the LCL converter vary in a very complex nature. Even under pure, real, reflected resistance conditions, one leg operates with huge diode reverse recovery losses (capacitive switching) and the other leg operates with conventional hard characteristics (inductive switching) [5]. In addition, the switching characteristics of each semiconductor device strongly depend on the operating temperature and internal device parameters that have relatively large discrepancies. Furthermore, from the highest efficiency standpoint, the results are very good even with this assumption and will be verified later with experimental results.

To aid the explanation of the analysis, Figure 6 is used. The secondary decoupling circuit is broken into two parts, one for the resonant tank $\left(\eta_{\mathrm{r} 2}\right)$ and the other for the boost converter $\left(\eta_{\mathrm{b} 2}, \eta_{2 \mathrm{c}}\right)$. For the boost converter, the conduction losses in semiconductor devices are modeled separately into two parts, one being the forward voltage drop at zero current $\left(\mathrm{V}_{\text {rd_on }}\right.$, $\left.\mathrm{V}_{\text {bs_on, }}, \mathrm{V}_{\text {bd_on }}\right)$, and the other being the equivalent linear resistance in series. The efficiency of the boost converter can now be analyzed separately as long as the efficiency is relatively high. It should be noted that $\mathrm{R}_{\mathrm{Ldc}}$ comprises the summation of the ESR in $\mathrm{L}_{\mathrm{dc}}$ and the linear resistance of the diodes in the rectifier bridge. The inductor current ripple is assumed to be zero to simplify the analysis.

The efficiency of the boost converter, neglecting the voltage drops after the rectifier is given by:

$$
\eta_{b 2}=\frac{P_{\text {out }}}{P_{\text {out }}+P_{\text {losses }}}=\frac{P_{\text {out }}}{P_{\text {out }}+P_{\text {Ldc }}+P_{\text {switch }}+P_{\text {diode }}}
$$

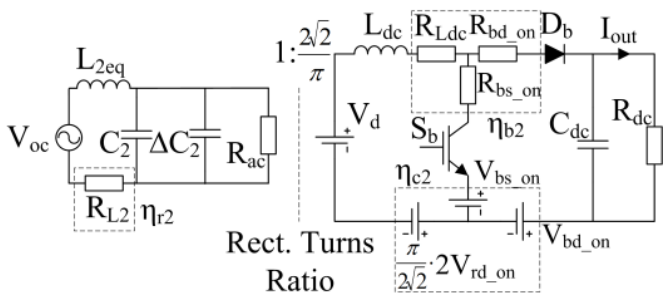

Figure 6. Equivalent efficiency model circuit diagram of secondary decoupling pickup (Figure 5).

Here only the linear resistance is considered and expanding (11) will result in:

$$
\eta_{b 2}=\frac{1}{1+\frac{R_{L d c}+D R_{\text {bs_on }}+(1-D) R_{b d \_o n}}{(1-D)^{2} R_{d c}}}
$$

By assuming $R_{b s_{-} \text {on }}$ is approximately equal to $R_{b d \_n}$, can be simplified to:

$$
\eta_{b 2}=\frac{1}{1+\frac{8 \omega C_{2}\left(R_{L d c}+R_{b d \_o n}\right)}{\pi^{2} Q_{2 v}}}
$$

Now, the losses due to the forward voltage drop of the devices neglecting the resistances can be derived in a similar manner, and by assuming $\mathrm{V}_{\mathrm{bs} \_ \text {on }}$ and $\mathrm{V}_{\mathrm{bd} \_ \text {on }}$ are similar, the efficiency can be expressed as:

$$
\eta_{c 2}=\frac{1}{1+\frac{\pi V_{\text {rd_on }}+\sqrt{2} V_{\text {bd_on }}}{\sqrt{2}(1-D) V_{\text {out }}}}
$$

Next, for the secondary resonant circuit, the detuning effect due to pad inductance variations is considered. To simplify the mathematics, the pad inductance is mathematically treated as a constant and the parallel tuning capacitor is treated as a variable. In addition, the ESR of the tuning capacitors is neglected as their losses are an order of magnitude lower than other components. The equation for the magnitude of $\mathrm{I}_{2}$ is:

where

$$
\left|I_{2}\right|=I_{a c} \sqrt{1+Q_{2 v}{ }^{2}(1+\alpha)^{2}}
$$

$$
\alpha=\left|\Delta C_{2} / C_{2}\right|
$$

Following the approach proposed in (11) and using (15), the efficiency of only the secondary resonant tank is given by:

$$
\eta_{r 2}=\frac{1}{1+\frac{\omega C_{2} R_{L 2}}{Q_{2 v}}\left(1+Q_{2 v}{ }^{2}(1+\alpha)^{2}\right)}
$$

Now multiplying (12), (14) and (17) will result in the efficiency of the secondary decoupling circuit. The next derivation is to determine the efficiency of the LCL converter and resonant network. The equivalent circuit shown in Figure 7 is used to model the losses. The efficiency analysis is again broken down between the resistance and voltage drop.

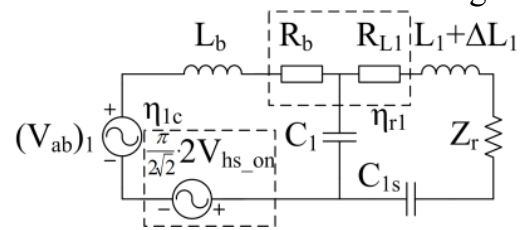

Figure 7. Equivalent efficiency model circuit diagram of primary LCL converter (Figure 4).

Firstly, to calculate $Z_{r}$, the parallel impedance of a secondary detuned resonant circuit needs to be derived. It is given by:

$$
Z_{p}=R_{a c} \| \frac{1}{j \omega \Delta C_{2}}=\frac{R_{a c}\left(1-j Q_{2 v} \alpha\right)}{1+Q_{2 v}{ }^{2} \alpha^{2}}
$$


Note that all the ESR losses on the secondary are neglected, because their values are much smaller than the reactance and load resistance components. Hence, $\mathrm{I}_{2}$ is given by:

$$
I_{2}=\frac{V_{o c}-V_{a c 2}}{j \omega L_{2}}=\frac{j \omega M I_{1}-\frac{M}{L_{2 e q}} I_{1} \frac{R_{a c}\left(1-j Q_{2 v} \alpha\right)}{1+Q_{2 v}{ }^{2} \alpha^{2}}}{j \omega L_{2 e q}}
$$

From first principles the reflected impedance is:

$$
Z_{r}=\frac{\omega^{2} M^{2} I_{2}}{V_{o c}}=\frac{\omega M^{2}}{L_{2 e q}} \frac{Q_{2 v}}{1+Q_{2 v}{ }^{2} \alpha^{2}}+j \frac{\omega M^{2}}{L_{2 e q}}\left(-1-\frac{Q_{2 v}{ }^{2} \alpha}{1+Q_{2 v}{ }^{2} \alpha^{2}}\right)
$$

It should be noted that (20) simplifies down to (4) if $\Delta \mathrm{C}_{2}$ is set to zero. Similar to before, the linear resistance losses are separated from the forward voltage drop at zero current. By using a similar approach as in (11), the efficiency for the primary considering only the linear resistance losses is:

$$
\eta_{r 1}=\frac{1}{1+\frac{R_{L 1}+R_{b} \omega^{2} C_{1}{ }^{2}\left(\left(R_{L 1}+\operatorname{Re}\left(Z_{r}\right)\right)^{2}+\left(\omega \Delta L_{1}+\operatorname{Im}\left(Z_{r}\right)\right)^{2}\right)}{\operatorname{Re}\left(Z_{r}\right)}}
$$

Similar to (13), the efficiency due to forward voltage drop is given by:

$$
\eta_{c 1}=1-\frac{\pi V_{\text {hs_on }}}{\omega L_{b} \sqrt{2 P_{\text {out }} / \operatorname{Re}\left(Z_{r}\right)}}
$$

By grouping (13), (14), (17), (21) and (22) the overall system efficiency is given by:

$$
\eta=\eta_{r 1} \cdot \eta_{c 1} \cdot \eta_{r 2} \cdot \eta_{b 2} \cdot \eta_{c 2}
$$

By computing the maximum of (23), the highest efficiency point can be found. However, this function is much higher than fourth order against $\mathrm{Q}_{2 \mathrm{v}}$ which means an analytical solution of a global maximum cannot be directly determined. Fortunately, through extensive analysis, this function would always have a global maximum and using a simple detection routine outlined in Section III.C, the maximum can be found. The values for the analysis are listed in Table III. $R_{b}$ is the sum of the ESR of $L_{b}$ and the linear resistance of the switches. To determine variables $\mathrm{M}$ and $\alpha$, Figure 3 can be used. $\mathrm{Q}_{2 \mathrm{v}}$ is calculated using (8). In addition, an approximate $37 \mathrm{~W}$ was used to power two sets of FPGA controller and sensors for the primary and secondary of the $5 \mathrm{~kW}$ system.

TABLE III. System Parameters For Efficiency Analysis.

\begin{tabular}{|c|c|c|c|}
\hline Parameters & Values & Parameters & Values \\
\hline $\mathrm{R}_{\mathrm{Ldc}}$ & $0.0166 \Omega$ & $\mathrm{V}_{\text {rd on }}$ & $0.77 \mathrm{~V}$ \\
\hline $\mathrm{R}_{\text {bd on }}$ & $0.035 \Omega$ & $\mathrm{R}_{\mathrm{b}}$ & $0.1194 \Omega$ \\
\hline $\mathrm{V}_{\text {bd on }}$ & $0.95 \mathrm{~V}$ & $\mathrm{~V}_{\text {hs on }}$ & $0.9 \mathrm{~V}$ \\
\hline $\mathrm{R}_{\mathrm{L} 2}$ & $0.0569 \Omega$ & $\mathrm{R}_{\mathrm{L} 1}$ & $0.0636 \Omega$ \\
\hline
\end{tabular}

\section{B. Results and Discussion}

Practical experimental measurements are used to validate the analysis from the previous section. Figure 8 and Figure 9 show the analytical and experimental results against changes in duty cycle during operation under different coupling conditions. $\mathrm{Q}_{2 \mathrm{vm}}$ is the maximum $\mathrm{Q}_{2 \mathrm{v}}$ achievable and used to denote the specific loading condition. For example, $\mathrm{Q}_{2 \mathrm{vm}}$ refers to $5 \mathrm{~kW}$ output and $0.8 \mathrm{Q}_{2 \mathrm{vm}}$ refers to $4 \mathrm{~kW}$ output, and so on. For the experimental results, duty cycle is limited at higher $\mathrm{Q}_{2 \mathrm{v}}$ (load conditions), to keep within the component tolerances of the physical system. Although there are differences in the absolute values between predicted and measured efficiency, the duty cycle at which the highest efficiency occurs is nearly the same and the slopes of the waveforms are nearly identical.
The large differences in efficiency value at lower power are due to the assumption of neglecting the switching losses in the system. When switching losses are included in the system level simulation, it directly matches on top of the experimental results; however, it is not shown here for purposes of clarity. Using these figures, a direct comparison between the efficiency of each control scheme is possible. For primary side control, duty cycle is always maintained at zero, and it can be seen that at lower $\mathrm{Q}_{2 \mathrm{vm}}$, the efficiency obtained is definitively lower than the optimal peak that appears in the measurement. For secondary side control, the duty cycle is controlled to keep the output voltage constant against load resistance variations by keeping $D=\left(1-Q_{2 v} / Q_{2 v m}\right)$. This is essentially the same control law described in Section III.A. Similarly, it can be seen that the efficiency of secondary control is not optimal. To make a clear comparison, the experimental results from Figure 8 and Figure 9 are listed in Table IV. It can be seen when $\mathrm{k}=1.14 \mathrm{k}_{\min }$, primary control efficiency is slightly better than secondary control efficiency; however, the optimal control is better than both. When $\mathrm{k}=2 \mathrm{k}_{\min }$, the secondary control is better than the primary; however, the optimal is still the best. It should be noted that when $\mathrm{k}=2 \mathrm{k}_{\min }$ and $\mathrm{Q}_{2 \mathrm{v}}=0.2 \mathrm{Q}_{2 \mathrm{vm}}$ $\left(\mathrm{P}_{\text {out }}=1 \mathrm{~kW}\right)$, an efficiency improvement of $\sim 7 \%$ and loss reduction of $\sim 25 \%$ is achieved compared against secondary control.

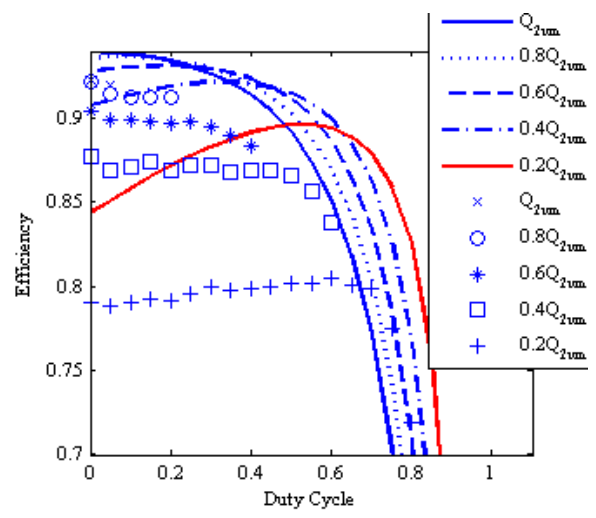

Figure 8. Efficiency of System @ $\mathrm{k}=1.14 \mathrm{k}_{\min }(\mathrm{v}=246 \mathrm{~mm}, \mathrm{~h}=0 \mathrm{~mm})$. Line represents analytically calculated results and markers represented experimental measured results. The data is taken for different loading conditions, when matched to a percentage of the maximum $\mathrm{Q}_{2 \mathrm{v}}$ loading

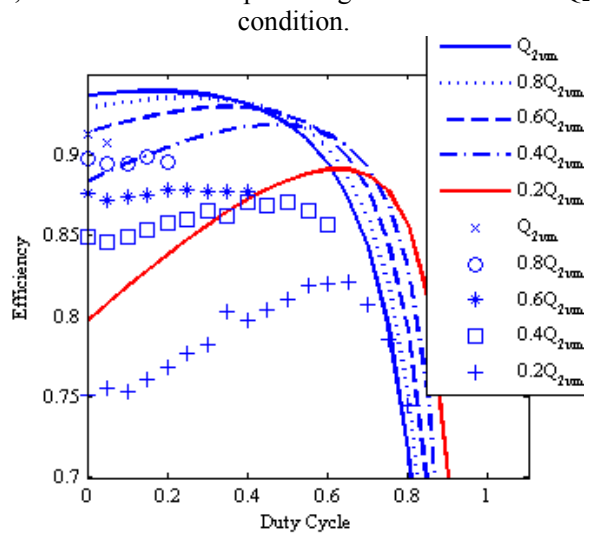

Figure 9. Efficiency of System @ $\mathrm{k}=2.0 \mathrm{k}_{\min }(\mathrm{v}=172 \mathrm{~mm}, \mathrm{~h}=0)$. Line represents analytically calculated results and markers represented experimental measured results. The data is taken for different loading conditions, when matched to a percentage of the maximum $\mathrm{Q}_{2 \mathrm{v}}$ loading condition. 
Table IV. System efficiency measurements at $1.14 \mathrm{k}_{\min }$ and $2 \mathrm{k}_{\min }$. The first value is analytical results and second value is experimental measurement.

\begin{tabular}{|c|c|c|c|c|c|c|}
\hline Efficiency & $\mathrm{k}$ & $\begin{array}{c}5 \mathrm{~kW} \\
(18 \Omega)\end{array}$ & $\begin{array}{c}4 \mathrm{~kW} \\
(22.5 \Omega)\end{array}$ & $\begin{array}{c}3 \mathrm{~kW} \\
(30 \Omega)\end{array}$ & $\begin{array}{c}2 \mathrm{~kW} \\
(45 \Omega)\end{array}$ & $\begin{array}{c}1 \mathrm{~kW} \\
(90 \Omega)\end{array}$ \\
\hline Primary & $1.14 \mathrm{k}_{\mathrm{m}}$ & $0.940 /$ & $0.937 /$ & $0.928 /$ & $0.907 /$ & $0.844 /$ \\
& & 0.923 & 0.922 & 0.904 & 0.877 & 0.791 \\
\hline Secondary & $1.14 \mathrm{k}_{\mathrm{m}}$ & $0.940 /$ & $0.935 /$ & $0.924 /$ & $0.900 /$ & $0.825 /$ \\
& & 0.923 & 0.913 & 0.883 & 0.837 & 0.719 \\
\hline Optimal & $1.14 \mathrm{k}_{\mathrm{m}}$ & $0.940 /$ & $0.937 /$ & $0.931 /$ & $0.922 /$ & $0.896 /$ \\
& & 0.923 & 0.922 & 0.904 & 0.877 & 0.804 \\
\hline Primary & $2 \mathrm{k}_{\mathrm{m}}$ & $0.937 /$ & $0.929 /$ & $0.914 /$ & $0.883 /$ & $0.797 /$ \\
& & 0.912 & 0.898 & 0.876 & 0.850 & 0.751 \\
\hline Secondary & $2 \mathrm{k}_{\mathrm{m}}$ & $0.937 /$ & $0.935 /$ & $0.929 /$ & $0.913 /$ & $0.857 /$ \\
& & 0.912 & 0.896 & 0.877 & 0.856 & 0.744 \\
\hline Optimal & $2 \mathrm{k}_{\mathrm{m}}$ & $0.938 /$ & $0.936 /$ & $0.930 /$ & $0.919 /$ & $0.891 /$ \\
& & 0.912 & 0.899 & 0.878 & 0.871 & 0.820 \\
\hline
\end{tabular}

For a typical IPT system, one may assume that the highest efficiency is achieved when the minimum primary track current or lowest duty cycle is used for the required power transfer. However, due to the high conduction losses in the Hbridge in (21) and (22) at low $\sigma$, the highest efficiency no longer occurs at the minimum primary current. To illustrate the large efficiency differences at $\mathrm{k}=2 \mathrm{k}_{\min }$ and $\mathrm{Q}_{2 \mathrm{v}}=0.2 \mathrm{Q}_{2 \mathrm{~m}}$, the RMS values of the key waveforms are shown in Figure 10. It can be seen that the highest efficiency, which occurs at $\mathrm{D}=0.6$ in Figure 9, corresponds very close to the minimum of the sum of $\mathrm{I}_{\mathrm{b}} \mathrm{I}_{1}$ and $\mathrm{I}_{2}$ in Figure 10. In comparison to primary side control, $I_{1}$ and $I_{2}$ are much smaller for optimal control. In comparison to secondary side control, $\mathrm{I}_{\mathrm{b}}$ is much smaller for optimal control.

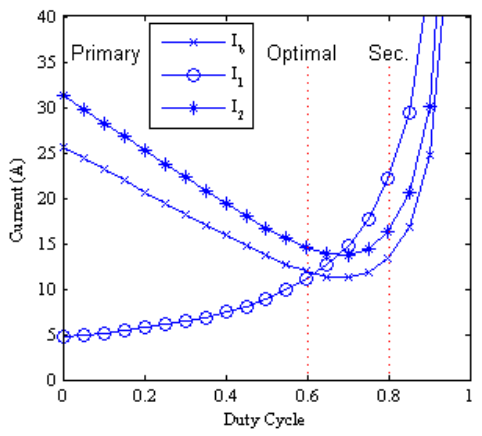

Figure 10. Current Values for waveforms $\mathrm{I}_{\mathrm{b}}, \mathrm{I}_{1}$, and $\mathrm{I}_{2}$ for $\mathrm{Q}_{2 \mathrm{v}}=0.2 \mathrm{Q}_{2 \mathrm{vm}}$ and $\mathrm{k}=2 \mathrm{k}_{\min }$ for different control schemes.

The magnetic field measurements meet the stringent ICNIRP standards by using the measurement technique proposed by ARPANSA [12]. There are two limits to meet: 1) Absolute maximum magnetic field exposed to the body must not exceed $27.3 \mu \mathrm{T}$ and 2) The average field strength by taking measurements at the head, chest, groin and knees must be below $6.25 \mu \mathrm{T}$. Figure 11 shows that the absolute maximum magnetic field strength can be met at $0.82 \mathrm{~m}$, which is less than half of the width of a typical passenger vehicle. The measurement was taken for all possible operating conditions and the worst case alignment conditions are shown in Figure 11. Figure 12 shows that the body average of $4.36 \mu \mathrm{T}$ is measured using the four point measurement and as a standard case scenario [12], a minimum height female of $1500 \mathrm{~mm}$ is used as the worst case. Note that maximum and average field strength shown here corresponds to the absolute worst case for all height and misalignment conditions.

The system level charging efficiency from $400 \mathrm{~V}$ DC to $300 \mathrm{~V}$ DC is shown in Figure 13 for a range of vertical and horizontal heights. This efficiency does not include the front PFC and rectification stage (Figure 1), but with recent publications [36], it can be shown that the efficiency from this stage can reach as high as $98 \%$. Factoring this component, the efficiency during normal operation over a wide range of coupling conditions can still be around or above $90 \%$ from grid to battery. This practical result is an important achievement as it shows that recent advances in IPT and device technology have allowed level 2 inductive charging to reach very high efficiencies. Thus, previous assumptions that inductive charging is much less efficient than plug-in systems no longer apply.

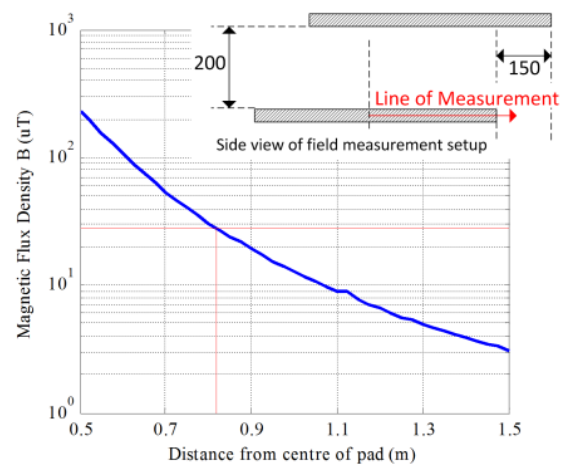

Figure 11. Magnetic field measurement results for $5 \mathrm{~kW}$ system operating under worst conditions. The highest field strength was found at vertical height of $200 \mathrm{~mm}$ and horizontal misalignment of $150 \mathrm{~mm}$.

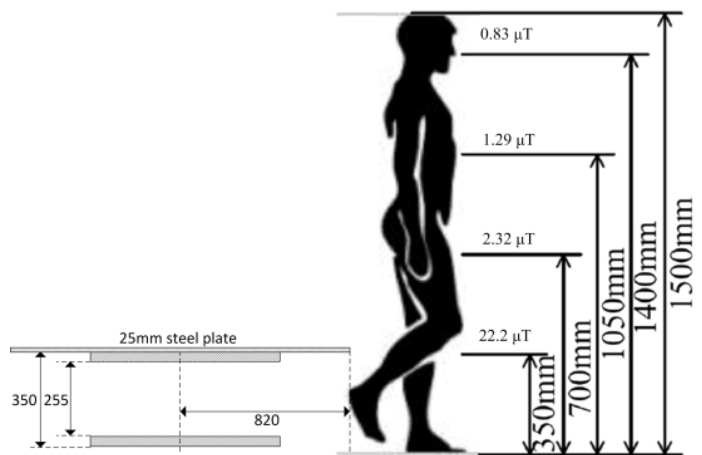

Figure 12. Body average measurement from 4 measurement points on a $1500 \mathrm{~mm}$ tall female human body. The highest field strength was found at vertical height of $255 \mathrm{~mm}$ and zero horizontal misalignment.

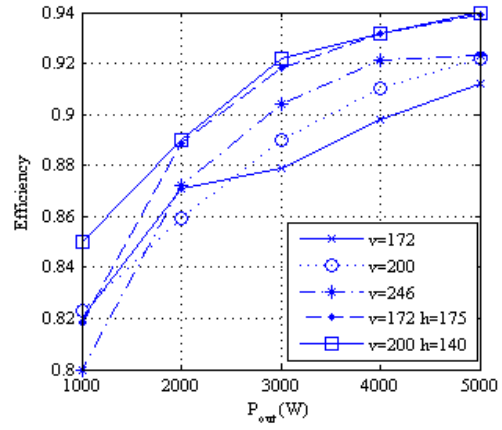

Figure 13. Efficiency measurement under a wide range of operating conditions. $\mathrm{v}=172$ is for a vertical height of $172 \mathrm{~mm}$ with zero horizontal misalignment. $\mathrm{v}=200, \mathrm{~h}=140$ is for a vertical height of $200 \mathrm{~m}$ and horizontal misalignment of $140 \mathrm{~mm}$. 
The operating waveforms are shown in Figure 14 and Figure 15 for the two coupling conditions of $k=2 k_{\min }$ and $\mathrm{k}=1.14 \mathrm{k}_{\min }$. At the maximum of $5 \mathrm{~kW}$, the duty cycle is set to zero and the RMS waveforms are much higher than at $2 \mathrm{~kW}$. When $\mathrm{k}=2 \mathrm{k}_{\min }$, the bridge current is much higher than $\mathrm{k}=1.14 \mathrm{k}_{\min }$, because a higher current is required to compensate for the low $\mathrm{AC}$ input voltage $\left(\mathrm{V}_{\mathrm{ab}}\right)_{1}$ from the $\mathrm{H}$-bridge, which is limited by the low conduction angle of the LCL converter to reduce primary track current shown in (3). Note that for optimal efficiency control outlined in Section III.A, a $2 \mathrm{~kW}$ power corresponds to a duty cycle of around 0.4 .

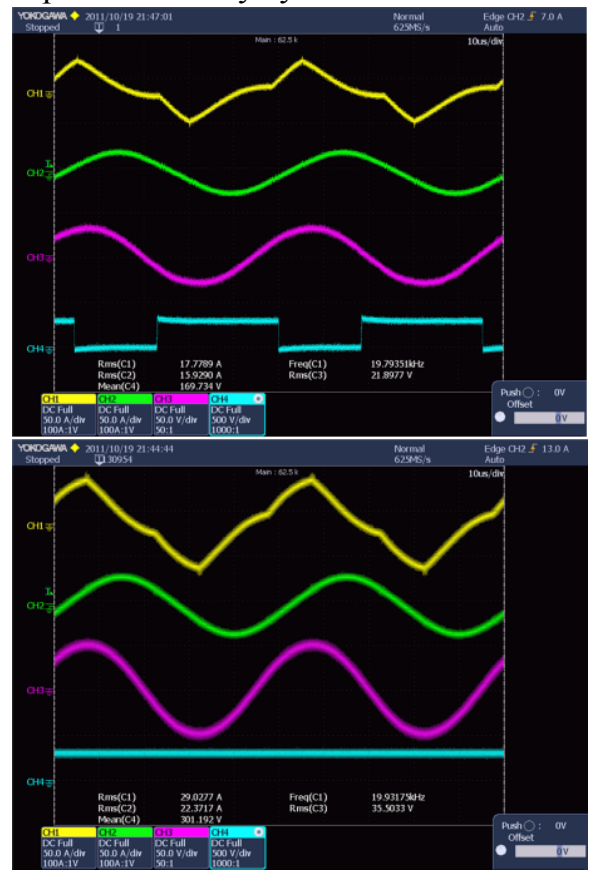

Figure 14. (Top) $\mathrm{P}=2 \mathrm{~kW}$, (Bottom) $\mathrm{P}=5 \mathrm{~kW} @ \mathrm{v}=172 \mathrm{~mm} \mathrm{~h}=0 \mathrm{~mm}$. Top to bottom trace, $I_{b}$ (Figure 4), $I_{1}$ (Figure 4), $I_{2}$ (Figure 5), and $V_{s}$ (Figure 5) (inverse of duty cycle). $\mathrm{k}=2.0 \mathrm{k}_{\min }$.

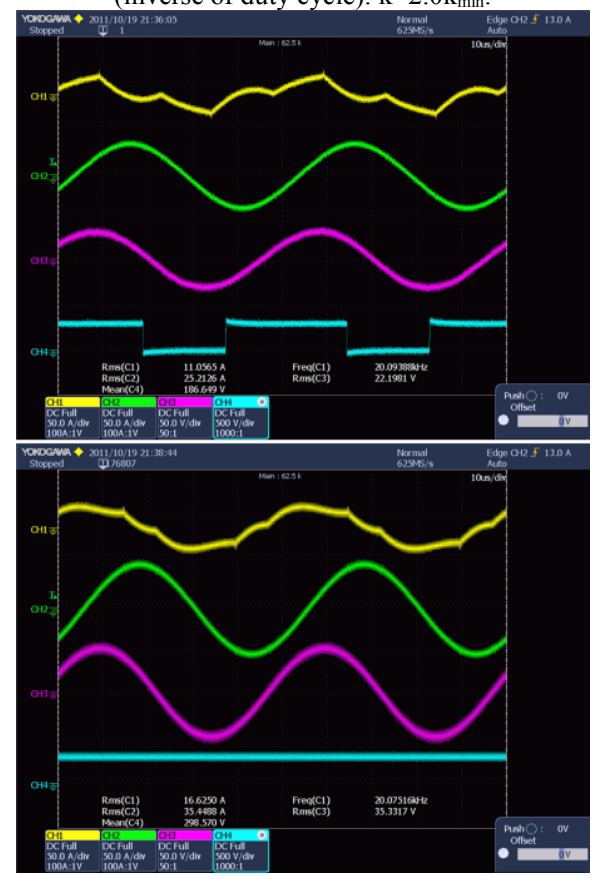

Figure 15. (Top) $\mathrm{P}=2 \mathrm{~kW}$, (Bottom) $\mathrm{P}=5 \mathrm{~kW} @ \mathrm{v}=246 \mathrm{~mm} \mathrm{~h}=0 \mathrm{~mm}$. Top to bottom trace, $I_{b}$ (Figure 4), $I_{1}$ (Figure 4), $I_{2}$ (Figure 5), and $V_{s}$ (Figure 5) (inverse of duty cycle). $\mathrm{k}=1.14 \mathrm{k}_{\min }$.

\section{Practical controller implementation}

To practically implement this system, the controller block diagram shown in Figure 16 is used. The duty cycle D is used as the primary control variable (inner loop) and the conduction angle $\sigma$ is constantly updated to keep the output power (or current) in regulation (outer loop).

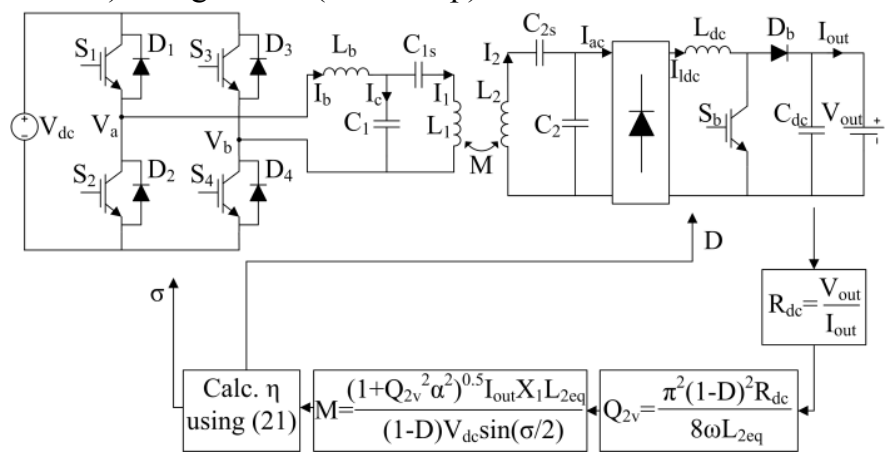

Figure 16. Controller block diagram for optimal efficiency.

The equivalent load resistance of the battery can be easily determined by measuring the battery voltage and the charging current. These two sensors are necessary for safety reasons when charging large batteries for EVs, hence no additional hardware is needed. To determine the coupling coefficient, observer equations can be directly used to predict its operating value. Firstly, the track current can be determined, perhaps through measurement using a current transformer (CT). However, if the PFC stage can maintain a constant 400V DC bus during operation, it is possible to directly estimate $\mathrm{I}_{1}$ using (3) without any extra CT. By using the estimated track current, $\mathrm{M}$ (and k) can be directly determined when $\mathrm{V}_{\mathrm{dc}}, \mathrm{V}_{\text {out }}$ and $\mathrm{I}_{\text {out }}$ are is measured. The equation that links them together is:

$$
M=\frac{\sqrt{1+Q_{2 v}{ }^{2} \alpha^{2}}}{1-D} \frac{I_{\text {out }} X_{1}}{V_{d c} \sin (\sigma / 2)} L_{2 e q}
$$

Figure 17 shows that the mutual inductance (or coupling) can be determined without much error over a wide range of load and duty cycle conditions.

Estimates of the system parameters in Table III are required for optimal efficiency control using (23). It is possible during manufacturing to directly measure the ESR and forward voltage values of each component and then program the controller for each unit with the measured parasitic values. The potential danger of this technique is that the ESR of the two IPT pads can vary if stray metal objects are bought into close proximity during operation. There are several ways to accurately detect pad ESR during operation; however, this problem is outside the scope of this paper.

Alternatively, by installing an input voltage and current sensor before the LCL converter with a nominal added cost, the input power can be measured directly. With access to the input and output power of the system, the efficiency can be determined and the optimum can be found by searching for the peak. This is the practical implementation approach taken in this paper for the closed loop controller. Although it can be argued that measuring efficiency in this way is not very accurate, the general trend can still be determined using sensors that have $1 \%$ measurement error. The peak of the function shown in Figure 8 can be tracked quite accurately. 
In this paper, transient analysis or operation is not shown, as transient performance for inductive charging systems can generally be neglected. The battery usually takes hours to charge. Once parked, the coupling is fixed; hence the system can be treated with very long time constants. This $5 \mathrm{~kW}$ IPT system takes a few seconds to reach its optimal charging state; however, this is negligible compared to the overall charging cycle.

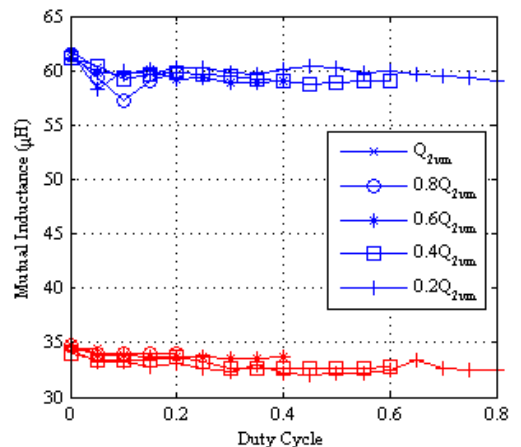

Figure 17. Coupling coefficient estimation using (24). Blue trace is for $\mathrm{k}=2 \mathrm{k}_{\min }(\mathrm{M}=60 \mu \mathrm{H})$ and Red trace is for $\mathrm{k}=1.14 \mathrm{k}_{\min }(\mathrm{M}=34.2 \mu \mathrm{H})$

\section{Conclusion}

This paper outlines the design and implementation of a practical $5 \mathrm{~kW}$ EV inductive charging system with a grid to battery efficiency of more than $90 \%$ at a range of operating heights from $175-265 \mathrm{~mm}$. In addition, the high efficiency is maintained operating with horizontal misalignment for driver parking tolerances. A new control strategy of achieving the most optimal efficiency during operation is derived and compared to conventional primary and secondary side control. Under lighter load conditions, an efficiency improvement of up to $7 \%$ is possible when using the newly proposed control scheme.

\section{REFERENCES}

[1]J. T. Boys, G. A. Covic and A. W. Green, "Stability and control of inductively coupled power transfer systems," IEE Proceedings - Electric Power Applications, vol. 147, no. 1, pp. 37-43, 2000.

[2]N. A. Keeling, G. A. Covic and J. T. Boys, "A Unity-Power-Factor IPT Pickup for High-Power Applications," IEEE Transactions on Industrial Electronics, vol. 57, no. 2, pp. 744-751, 2010.

[3] G. Elliott, S. Raabe, G. A. Covic and J. T. Boys, "Multiphase Pickups for Large Lateral Tolerance Contactless Power-Transfer Systems," IEEE Transactions on Industrial Electronics, vol. 57, no. 5, pp. 1590-1598, 2010. [4]M. Borage, S. Tiwari and S. Kotaiah, "Analysis and design of an LCL-T resonant converter as a constant-current power supply," IEEE Transactions on Industrial Electronics, vol. 52, no. 6, pp. 1547-1554, 2005.

[5]H. H. Wu, A. Gilchrist, K. Sealy, P. Israelsen and J. Muhs, "Design of Symmetric Voltage Cancellation Control for LCL converters in Inductive Power Transfer Systems," in IEEE International Electric Machines \& Drives Conference (IEMDC), 2011, 2011, pp. 866-871.

[6]C. C. Chan, "The State of the Art of Electric, Hybrid, and Fuel Cell Vehicles," Proceedings of the IEEE, vol. 95, no. 4, pp. 704-718, 2007.

[7]SAE, "SAE Electric Vehicle and Plug in Hybrid Electric Vehicle Conductive Charge Coupler," SAE J1772 Standard, 2001.

[8]M. Eghtesadi, "Inductive power transfer to an electric vehicle-analytical model," in 1990 IEEE 40th Vehicular Technology Conference, 1990, pp. 100104.

[9] C.-S. Wang, O. H. Stielau and G. A. Covic, "Design considerations for a contactless electric vehicle battery charger," IEEE Transactions on Industrial Electronics, vol. 52, no. 5, pp. 1308-1314, Oct. 2005, 2005.
[10] H. Chang-Yu, J. T. Boys, G. A. Covic and M. Budhia, "Practical considerations for designing IPT system for EV battery charging," in IEEE Vehicle Power and Propulsion Conference, 2009. VPPC '09. , 2009, pp. $402-$ 407.

[11] M. Budhia, G. Covic and J. Boys, "A new IPT magnetic coupler for electric vehicle charging systems," in 36th Annual Conference on IEEE Industrial Electronics Society, IECON 2010, 2010, pp. 2487-2492.

[12] M. Budhia, G. Covic and J. Boys, "Design and Optimisation of Circular Magnetic Structures for Lumped Inductive Power Transfer Systems," IEEE Transactions on Power Electronics, vol. PP, no. 99, pp. 1-1, 2011.

[13] M. Budhia, G. A. Covic, J. T. Boys and C.-Y. Huang, "Development and evaluation of single sided flux couplers for contactless electric vehicle charging," in IEEE Energy Conversion Congress and Expo (ECCE), 2011, 2011, pp. 614-621.

[14] M. Chigira, Y. Nagatsuka, Y. Kaneko, S. Abe, T. Yasuda and A. Suzuki, "Small-Size Light-Weight Transformer with New Core Structure for Contactless Electric Vehicle Power Transfer System," in IEEE Energy Conversion Congress and Expo (ECCE), 2011, 2011, pp. 260-266.

[15] S. Lee, J. Huh, C. Park, N.-S. Choi, G.-H. Cho and C.-T. Rim, "OnLine Electric Vehicle using inductive power transfer system," in IEEE Energy Conversion Congress and Exposition (ECCE), 2010, pp. 1598-1601.

[16] H. Jin, L. Wooyoung, C. Gyu-Hyeong, L. Byunghun and R. Chun-Taek, "Characterization of novel Inductive Power Transfer Systems for On-Line Electric Vehicles," in Twenty-Sixth Annual IEEE Applied Power Electronics Conference and Exposition (APEC), 2011, 2011, pp. 1975-1979.

[17] J. Huh, S. Lee, C. Park, G.-H. Cho and C.-T. Rim, "High performance inductive power transfer system with narrow rail width for On-Line Electric Vehicles," in IEEE Energy Conversion Congress and Exposition (ECCE), 2010, pp. 647-651.

[18] L. Sungwoo, L. Wooyoung, H. Jin, K. Hyun-Jae, P. Changbyung, C. Gyu-Hyeong and R. Chun-Taek, "Active EMF cancellation method for I-type pickup of On-Line Electric Vehicles," in Twenty-Sixth Annual IEEE Applied Power Electronics Conference and Exposition (APEC), 2011, 2011, pp. 19801983.

[19] Z. Pantic, S. Bai and S. Lukic, "A New Tri-State-Boost-Based Pickup Topology for Inductive Power Transfer," in IEEE Energy Conversion Congress and Expo (ECCE), 2011, 2011, pp. 3495-3502.

[20] Z. Pantic, S. Bhattacharya and S. Lukic, "Optimal resonant tank design considerations for primary track compensation in Inductive Power Transfer systems," in IEEE Energy Conversion Congress and Exposition (ECCE), 2010 2010, pp. 1602-1609.

[21] S.-H. Lee and R. D. Lorenz, "Development and validation of model for $95 \%$ efficiency, $220 \mathrm{~W}$ wireless power transfer over a $30 \mathrm{~cm}$ air-gap," in IEEE Energy Conversion Congress and Exposition (ECCE), 2010, pp. 885-892.

[22] S.-H. Lee and R. D. Lorenz, "A Design Methodology for Multi-kW, Large Airgap, MHz Frequency, Wireless Power Transfer Systems," in IEEE Energy Conversion Congress and Expo (ECCE), 2011, 2011, pp. 3503-3510.

[23] F. Nakao, Y. Matsuo, M. Kitaoka and H. Sakamoto, "Ferrite core couplers for inductive chargers," in Proceedings of the Power Conversion Conference, 2002. PCC Osaka 2002., 2002, pp. 850-854 vol.2.

[24] H. H. Wu, A. Gilchrist, K. Sealy, P. Israelsen and J. Muhs, "A review on inductive charging for electric vehicles," in IEEE International Electric Machines \& Drives Conference (IEMDC), 2011, 2011, pp. 143-147.

[25] H. H. Wu, G. A. Covic, J. T. Boys and A. P. Hu, "A 1kW inductive charging system using AC processing pickups," in 6th IEEE Conference on Industrial Electronics and Applications (ICIEA), 2011 2011, pp. 1999-2004.

[26] H. Chang-Yu, J. T. Boys, G. A. Covic and R. Saining, "LCL pick-up circulating current controller for inductive power transfer systems," in IEEE Energy Conversion Congress and Exposition (ECCE), 2010 2010, pp. 640646.

[27] Y. Nagatsuka, N. Ehara, Y. Kaneko, S. Abe and T. Yasuda, "Compact contactless power transfer system for electric vehicles," in International Power Electronics Conference (IPEC), 2010 2010, pp. 807-813.

[28] O. H. Stielau and G. A. Covic, "Design of loosely coupled inductive power transfer systems," in International Conference on Power System Technology, 2000. Proceedings. PowerCon 2000., 2000, pp. 85 - 90.

[29] G. A. Covic, J. T. Boys, A. M. W. Tam and J. C. H. Peng, "Self tuning pick-ups for inductive power transfer," in IEEE Power Electronics Specialists Conference, 2008. PESC 2008., 2008, pp. 3489-3494.

[30] J. T. Boys, C. Y. Huang and G. A. Covic, "Single-phase unity powerfactor inductive power transfer system," in IEEE Power Electronics Specialists Conference, 2008. PESC 2008., 2008, pp. 3701-3706.

[31] Y. Xu, J. T. Boys and G. A. Covic, "Modeling and controller design of ICPT pick-ups," 2002. 
[32] P. Si and A. P. Hu, "Analyses of DC Inductance Used in ICPT Power Pick-Ups for Maximum Power Transfer," in 2005 IEEE/PES Transmission and Distribution Conference and Exhibition: Asia and Pacific, 2005 pp. 1-6

[33] P. Si, A. P. Hu, J. W. Hsu, M. Chiang, Y. Wang, S. Malpas and D. Budgett, "Wireless Power Supply for Implantable Biomedical Device Based on Primary Input Voltage Regulation," in 2nd IEEE Conference on Industrial Electronics and Applications, 2007. ICIEA 2007., 2007, pp. 235 - 239.

[34] G. B. Joung and B. H. Cho, "An energy transmission system for an artificial heart using leakage inductance compensation of transcutaneous transformer," IEEE Transactions on Power Electronics, vol. 13, no. 6, pp. 1013-1022, Nov. 1998, 1998.

[35] P. Si, A. P. Hu, S. Malpas and D. Budgett, "A Frequency Control Method for Regulating Wireless Power to Implantable Devices," IEEE Transactions on Biomedical Circuits and Systems, vol. 2, no. 1, pp. 22-29, March 2008, 2008.

[36] F. Musavi, W. Eberle and W. G. Dunford, "A High-Performance Single-Phase Bridgeless Interleaved PFC Converter for Plug-in Hybrid Electric Vehicle Battery Chargers," IEEE Transactions on Industry Applications, vol. 47, no. 4, pp. 1833-1843, 2011.

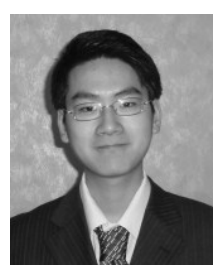

Hunter Wu graduated with a Ph.D. in Electrical and Electronic Engineering and Bioengineering (2010) and a B.E. in Electrical Engineering (2008) from the University of Auckland. He was awarded the Senior Scholar (equivalent to being ranked $\# 1$ in major) and the Top Achiever Doctoral Scholarship (equivalent to the Fullbright Scholarship), both in 2008. He now serves as the principal investigator and research scientist at EDL over the Wireless Energy And Power Conversion (WEAPC) branch. He has over a dozen peer-reviewed, IEEE international journal and conference publications. Dr. Wu was granted one patent and has 6 patents pending. He also received a Best Paper Award at the 6th IEEE ICIEA 2011 conference and serves as a technical journal reviewer for IEEE Transactions on Industrial Electronics, IEEE Transactions on Power Electronics, and Society of Automotive Engineers.

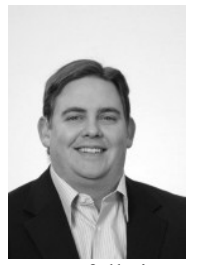

Kylee D. Sealy "Ky" Sealy has a strong background in electrical engineering with significant experience in system design and engineering project management. He earned his Master's degree in Engineering from Utah State University and has been involved in cutting-edge technology and program development over the last 7 years. Prior to joining the Energy Dynamics Laboratory Wireless Energy and Power Conversion team in June of 2010, Ky successfully ran a full-time engineering consulting and design company where he has earned a reputation for excellent engineering design worldwide in industries including aerospace, medical, fitness, power electronic, robotic, embedded computing, renewable energy, and consumer device industries to name a few. Ky has also been the Director of Engineering for two successful start-up companies and hopes to continue in the trend of successful technology upbringing.

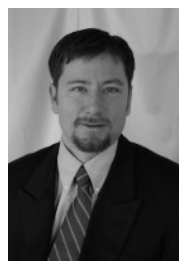

Aaron Gilchrist has extensive experience in thermal and mechanical engineering, research and program management. Mr. Gilchrist has been managing EDL's inductive power transfer program for the past two years, serving both as the program's thermal and mechanical engineer and acting branch lead. Prior to his work at EDL, Mr. Gilchrist worked at SDL defining mechanical and electrical interfaces on a critical calibration effort for the Missile Defense Agency (MDA). Other important roles include thermal analyst and lead thermal test engineer for Lockheed Martin's Mars Odyssey spacecraft. Mr. Gilchrist graduated with a M.S. in Mechanical Engineering in 2001 and is currently a $\mathrm{Ph}$.D. fellowship award winner at Utah State University, where he will receive his Ph.D. in hydraulics in 2012.

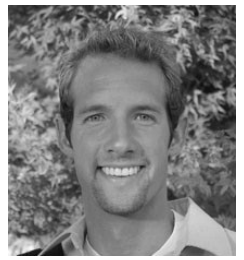

Dan Bronson graduated with a B.S. in Electrical Engineering from Utah State University in 2011. He now works with Energy Dynamics Lab in the Wireless Energy And Power Conversion (WEAPC) branch. His primary focuses are the embedded programming and control theory in relation to wireless power transfer. 